\title{
REACTIONS OF ENOLISABLE KETONES WITH DICHLOROISOCYANURIC ACID IN ABSENCE AND PRESENCE OF ADDED CHLORIDE IONS - A KINETIC STUDY
}

\author{
Y. Lakshman Kumar $^{1}$, R. Venkata $\mathrm{Nadh}^{2 *}$ and P.S. Radhakrishnamurti ${ }^{1}$ \\ ${ }^{1}$ Department of Chemistry, TJPS (PG) College, Guntur-522006, India \\ ${ }^{2}$ School of Biotechnology, Vignan University, Vadlamudi-522213, India
}

(Received July 13, 2013; revised June 29, 2014)

\begin{abstract}
Kinetics of reactions of enolisable ketones ( $\mathrm{S}=$ acetone/2-butanone) with dichloroisocyanuric acid (DCICA) were studied in aqueous acetic acid and perchloric acid media in absence and presence of added chloride ions. The reactions were found to be pseudo zero order and pseudo first order on [DCICA] in absence and presence of chloride ions respectively. Both in presence and absence of chloride ions, first order and fractional order in substrate and perchloric acid were observed respectively. An increase in the rate of reaction was observed with an increase in chloride ion concentration as well as acetic acid composition. The results were interpreted in terms of probable mechanisms involving (i) rate-determining enol formation from the conjugate acid of the ketone $\left(\mathrm{SH}^{+}\right)$in the absence of added chloride ions and (ii) rate-determining interaction of $\mathrm{SH}^{+}$with the most effective molecular chlorine species produced by the hydrolysis of DCICA (rather than a rate-determining interaction of enol with chlorine) in the presence of added chloride ions, prior to the rapid steps of product formation.
\end{abstract}

KEY WORDS: Dichloroisocyanuric acid, Acetone, 2-Butanone, Kinetics, Chloride ion, Enolisation

\section{INTRODUCTION}

Kinetics of oxidation of ketones by different N-halo oxidants like N-bromo succinimide [1, 2], 1,3-dichloro-5,5'-dimethylhydantoin [3], N-chlorosaccharin [4, 5], trichloroisocyanuric acid [6, 7], N-bromosaccharin [8] have received considerable attention. A thorough literature survey showed that till the date, reactions between dichloroisocyanuric acid (DCICA) and ketones were not studied. Hence, an attempt has been made to study the reactions of acetone and 2-butanone with DCICA in acetic acid-perchloric acid medium both in absence and presence of added chloride ions. The current study is aimed to learn the behavior of DCICA, i.e. whether it acts as a halogenating agent and/or oxidizing agent with the ketones.

\section{EXPERIMENTAL}

The substrates (acetone and 2-butanone) were of AR grade and were redistilled before use. Dichloroisocyanuric acid was obtained from Fluka. All other chemicals used were obtained from ExcelaR (Glaxo). The reaction was followed by estimating the concentration of unreacted DCICA by iodometry at $\mathrm{pH} 1-2$.

$\mathrm{C}_{3} \mathrm{O}_{3} \mathrm{~N}_{3} \mathrm{H}(\mathrm{Cl})_{2}+4 \mathrm{I}^{-}+2 \mathrm{H}^{+} \longrightarrow \mathrm{C}_{3} \mathrm{O}_{3} \mathrm{~N}_{3}(\mathrm{H})_{3}+2 \mathrm{I}_{2}+2 \mathrm{Cl}^{-}$

Compared to the rates of present reaction, self decomposition rates of DCICA were negligibly smaller under the conditions employed. The rate constants remained practically unaltered in air or in a de-aerated atmosphere. Only a representative set of the average values of kinetic data in aqueous acetic acid medium was presented here.

Product analysis and stoichiometry

The product analysis was carried out by using a reaction mixture of ketone $(10 \mathrm{mmol})$ and DCICA $(1 \mathrm{mmol})$. Reactants were taken in acetic acid-water mixture $(15: 85 \mathrm{v} / \mathrm{v})$ and the

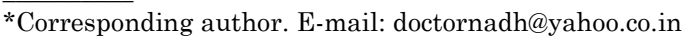


reaction mixture was allowed to stand for 24 hours to ensure completion of the reaction. Then the reaction mixtures were extracted with ether. The acetic acid in the ether layer was neutralized by using saturated sodium bicarbonate solution, washed with distilled water and dried over anhydrous sodium sulfate. Then ether layer was separated and evaporated. The organic products were subjected to spot tests and thin layer chromatographic analysis (silica gel, 1:1 mixture of benzene and light petroleum ether b.p. $40-60{ }^{\circ} \mathrm{C}$ ) which revealed the formation of oxidation products as formic acid and acetic acid for acetone, and for 2-butanone the product was acetic acid. Reaction mixtures containing varying proportions of DCICA and ketones were equilibrated at room temperature for 24 hours in the presence of $\mathrm{HClO}_{4}$. Determination of the un reacted DCICA by iodometric method showed 3:2 (DCICA:ketone) stoichiometry.

$\mathrm{RCH}_{2} \mathrm{COCH}_{3}+3 \mathrm{H}_{2} \mathrm{OCl}^{+}+3 \mathrm{H}_{2} \mathrm{O} \longrightarrow \mathrm{RCOOH}+\mathrm{CH}_{3} \mathrm{COOH}+3 \mathrm{HCl}+3 \mathrm{H}_{3} \mathrm{O}^{+}$ $\left(\mathrm{R}=\mathrm{CH}_{3}\right.$ or $\left.\mathrm{H}\right)$

\section{RESULTS AND DISCUSSION}

While the disappearance of DCICA in the absence of added chloride ions was pseudo-zero order in [DCICA] (Figure 1), the same reaction in the presence of added chloride ions exhibited pseudo-first order kinetics (Figure 2). Both in absence and presence of chloride ions, first order was observed in substrate and reaction rate increased with an increase in $\left[\mathrm{H}^{+}\right]$showing a fractional order (Tables 1 and 2).

The reaction rates were found to increase with an increase in the percentage of acetic acid in absence of added chloride ions (Table 1). The increase in the rate of oxidation with an increase in the polarity of the medium suggests a more polar transition state than the reactants. The dielectric constants (D) of water-acetic acid mixtures were calculated from the dielectric constants of pure solvents [9]. Plots of $\log \mathrm{k}$ versus 1/D were found to be linear with positive slopes, indicating an interaction between a positive ion and a dipolar molecule [10].

An increase in the rate of the reaction was observed with an increase in the concentration of added chloride ions (Table 2). In the presence of the added chloride ions, the reaction proceeded through a $\mathrm{Cl}^{-}$mediated route. The plots of $\log k_{1}$ versus $\log \left[\mathrm{Cl}^{-}\right]$were straight lines with a slope of 0.25 indicating a fractional order with respect to $\left[\mathrm{Cl}^{-}\right]$.

In order to understand the intervention of free radicals, the reaction was studied in presence of added acrylonitrile [11-13]. There was no induced polymerization of the acrylonitrile, as there was no formation of the precipitate and also it did not affect the rate of the reaction. The negative polymerization test indicates the absence of in situ generation of free radicals in the reaction mixture.

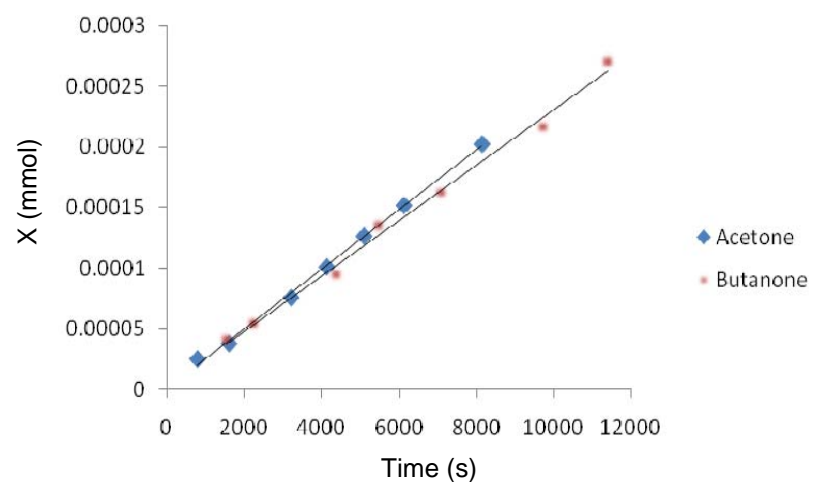

Figure 1. Plots for zero order dependence on oxidant (in absence of chloride). 


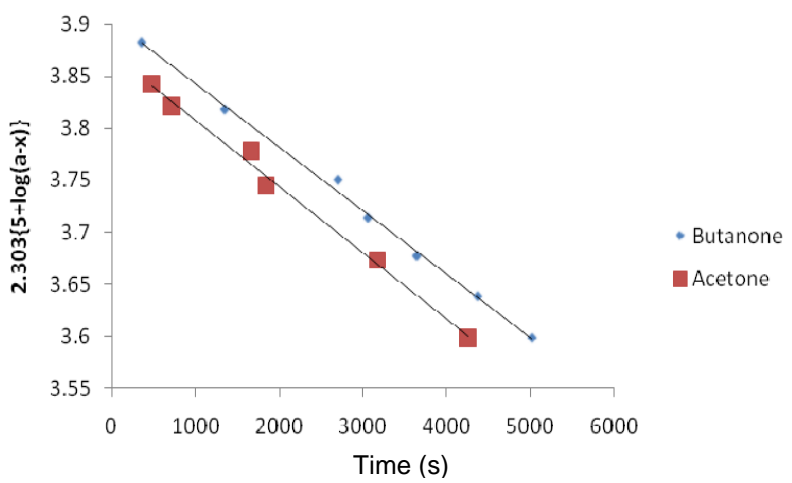

Figure 2. Plots for first order dependence on oxidant (in presence of chloride).

Table 1. Oxidation of acetone and 2-butanone by DCICA in absence of added chloride ions ([DCICA] $=$ $0.0005 \mathrm{M}$, [Ketone $]=0.005 \mathrm{M},\left[\mathrm{H}^{+}\right]=0.1 \mathrm{M}$, temperature $=35^{\circ} \mathrm{C}$, solvent composition $=15: 85$ $\left(\mathrm{AcOH}: \mathrm{H}_{2} \mathrm{O} v / \mathrm{v}\right)$.

\begin{tabular}{|c|c|c|c|}
\hline Variant & $\begin{array}{c}\text { Conc. of variant } \\
(\mathrm{mol})\end{array}$ & $\begin{array}{c}\mathrm{k}_{\mathrm{o}} \times 10^{8} \mathrm{~mol} \mathrm{~s}^{-1} \\
\text { (for acetone) }\end{array}$ & $\begin{array}{c}\mathrm{k}_{\mathrm{o}} \times 10^{8} \text { mol s}^{-1} \\
\text { (for 2-butanone) }\end{array}$ \\
\hline [Oxidant] & 0.00025 & 2.4 & 2.3 \\
& 0.00050 & 2.5 & 2.3 \\
& 0.00075 & 2.5 & 2.3 \\
\hline [Substrate] & 0.0050 & 2.5 & 2.3 \\
& 0.0125 & 6.6 & 4.8 \\
& 0.0250 & 12.5 & 9.8 \\
& 0.0375 & 19.4 & 14.2 \\
\hline Acid] & 0.0250 & 1.2 & 1.1 \\
& 0.0500 & 1.8 & 1.7 \\
& 0.1000 & 2.5 & 2.3 \\
& 0.1500 & 3.9 & 2.8 \\
\hline \multirow{2}{*}{ Solvent composition } & $15: 85$ & 2.5 & 2.3 \\
(AcOH: $\left.\mathrm{H}_{2} \mathrm{O} \mathrm{v} / \mathrm{v}\right)$ & $25: 75$ & 2.6 & 2.6 \\
& $45: 55$ & 2.9 & 2.7 \\
& $55: 45$ & 3.2 & 3.6 \\
& $70: 30$ & 4.8 & 4.6 \\
\hline Temperature $\left({ }^{\circ} \mathrm{C}\right)$ & 35 & 2.5 & 2.3 \\
& 40 & 3.6 & 3.3 \\
& 45 & 5.0 & 4.0 \\
& 50 & 8.4 & 7.3 \\
\hline
\end{tabular}

Effect of temperature on the reaction rate was studied in the temperature range $308 \mathrm{~K}$ to 323 $\mathrm{K}$ (Tables 1 and 2) and found that the rate increased with an increase in temperature. With the help of $\ln \mathrm{k}$ vs $1 / \mathrm{T}$ plots, Arrhenius equation and Gibbs-Helmholtz relationship, activation parameters like energy of activation $\left(\mathrm{E}_{\mathrm{a}}\right)$, enthalpy of activation $\left(\Delta \mathrm{H}^{\ddagger}\right)$, entropy of activation $\left(\Delta \mathrm{S}^{\neq}\right)$, free energy of activation $\left(\Delta \mathrm{G}^{\neq}\right)$and $\log _{10} \mathrm{P}_{\mathrm{Z}}$ were computed (Table 3 ). Slow kinetics is suggested from the values of energy of activation. Moderate values of energy of activation support the proposed mechanisms. Highly solvated nature of transition state is manifested from the positive values of $\Delta G^{\neq}$and $\Delta H^{\ddagger}$. Negative entropy explains (a) the formation of a compact and ordered transition state with fewer degrees of freedom and (b) a fraction of collisions are stringent leading to a slow decomposition of the rigid activated complex. 
Table 2. Oxidation of acetone and 2-butanone by DCICA in presence of added chloride ions ([DCICA] $=$ $0.0005 \mathrm{M}$, [Substrate $]=0.005 \mathrm{M},\left[\mathrm{Cl}^{-}\right]=0.00125 \mathrm{M},\left[\mathrm{H}^{+}\right]=0.1 \mathrm{M}$, temperature $=35^{\circ} \mathrm{C}$, solvent composition $=15: 85\left(\mathrm{AcOH}: \mathrm{H}_{2} \mathrm{O}\right.$ v/v).

\begin{tabular}{|c|c|c|c|}
\hline Variant & $\begin{array}{c}\text { Conc. of variant } \\
(\mathrm{mol})\end{array}$ & $\begin{array}{c}\mathrm{k}_{1} \times 10^{5} \mathrm{~s}^{-1} \\
\text { (for acetone) }\end{array}$ & $\begin{array}{c}\mathrm{k}_{1} \times 10^{5} \mathrm{~s}^{-1} \\
\text { (for 2-butanone) }\end{array}$ \\
\hline [Oxidant] & 0.00025 & 6.1 & 6.0 \\
& 0.00050 & 6.3 & 6.1 \\
\hline [Substrate] & 0.00075 & 6.3 & 6.3 \\
\hline & 0.0050 & 6.3 & 12.7 \\
& 0.0125 & 13.2 & 26.8 \\
& 0.0250 & 26.9 & 33.6 \\
\hline [Acid] & 0.0250 & 38.7 & 3.5 \\
& 0.0500 & 3.8 & 4.7 \\
& 0.1000 & 5.7 & 6.1 \\
& 0.1500 & 6.4 & 6.3 \\
\hline $\left.\mathrm{Cl}^{-}\right]$ & 0.00125 & 9.9 & 6.1 \\
& 0.00250 & 6.4 & 7.3 \\
& 0.0500 & 7.0 & 8.6 \\
\hline Temperature $\left({ }^{\circ} \mathrm{C}\right)$ & 35 & 10.0 & 6.1 \\
& 40 & 6.4 & 10.0 \\
& 45 & 11.3 & 12.4 \\
& 50 & 13.9 & 21.9 \\
\hline
\end{tabular}

Table 3. Arrhenius parameters for oxidation of acetone and 2-butanone.

\begin{tabular}{|l|c|c|c|c|c|}
\hline Substrate & $\begin{array}{c}\Delta \mathrm{E}^{\neq} \\
\mathrm{kJ} / \mathrm{mol}\end{array}$ & $\begin{array}{c}\Delta \mathrm{H}^{\neq} \\
\mathrm{kJ} / \mathrm{mol}\end{array}$ & $\begin{array}{c}-\Delta \mathrm{S}^{\mp} \\
\mathrm{J} / \mathrm{K} / \mathrm{mol}\end{array}$ & $\log _{10} \mathrm{P}_{\mathrm{Z}}$ & $\begin{array}{c}\Delta \mathrm{G}^{\neq} \\
\mathrm{kJ} / \mathrm{mol}\end{array}$ \\
\hline Acetone & 66.3 & 63.7 & 184.4 & 3.6 & 120.5 \\
\hline $\begin{array}{l}\text { Acetone } \\
\text { (in presence of chloride ions) }\end{array}$ & 69.6 & 67.1 & 107.7 & 7.6 & 100.2 \\
\hline 2-Butanone & 60.5 & 57.9 & 203.9 & 2.6 & 120.7 \\
\hline $\begin{array}{l}\text { 2-Butanone } \\
\text { (in presence of chloride ions) }\end{array}$ & 66.9 & 64.3 & 117.2 & 7.1 & 100.4 \\
\hline
\end{tabular}

Active oxidizing species in absence and presence of chloride ions

The reactive species of DCICA in acidic medium may be DCICA itself or $\mathrm{HOCl}$ or DCICAH ${ }^{+}$ or $\mathrm{H}_{2} \mathrm{OCl}^{+}$. The possibilities of both unprotonated and protonated (DCICA and DCICAH ${ }^{+}$) can be ruled out from the negative effect of cyanuric acid on the rate of reaction. Similarly, the role of $\mathrm{HOCl}$ as oxidizing species in the present reaction can be ruled out from the positive effect of $\left[\mathrm{H}^{+}\right]$on the rate of reaction. Hence, the only choice left under acidic conditions was $\mathrm{H}_{2} \mathrm{OCl}^{+}$as oxidising species. The increase in rate with an increase in $\left[\mathrm{H}^{+}\right]$indicates that probably, $\mathrm{HOCl}$ may enter into protonation equilibrium giving $\mathrm{H}_{2} \mathrm{OCl}^{+}$. Thus, reactive species may therefore, be assumed to be $\mathrm{H}_{2} \mathrm{OCl}^{+}$. This is in corroboration with the work of Anil Kumar and Sondu [14], who proposed that during hydrolysis of TCICA, the predominant species was found to be $\mathrm{HOCl}$ which may enter into protonation equilibria giving $\mathrm{H}_{2} \mathrm{OCl}^{+}$, thus the reactive species may be $\mathrm{HOCl}$ and $\mathrm{H}_{2} \mathrm{OCl}^{+}$. Similarly, the participation of hypohalous acidium ion in many electrophilic substitution and oxidation reactions was reported by Khan et al. [4].

The role of chloride ion in the kinetics of the oxidation of ketones by DCICA is very critical. With an increase in the concentration of chloride ion, an increase in the rate of the reaction was observed. For suggesting a most probable mechanism, identification of active oxidizing species is required. The reaction conditions will decide the nature of the active oxidizing species. The 
species with oxidizing character may vary depending on $\mathrm{pH}$ of the medium. Based on the experimental conditions, $\mathrm{Cl}_{2}, \mathrm{HOCl}, \mathrm{H}_{2} \mathrm{OCl}^{+}, \mathrm{DCICAH}^{+}$and DCICA itself can be the possible oxidizing species in aqueous solution. In the case of $\mathrm{N}$-halo oxidants, $\mathrm{HOCl}$ was the reactive oxidant species $[15,16]$. In this study, $\mathrm{H}_{2} \mathrm{OCl}^{+}$was the active oxidant in the absence of chloride ions. In the presence of chloride ions, the reaction was found to be catalyzed by both hydrogen and chloride ions. Hence, the molecular chlorine formed in acidic conditions can be assumed as the effective oxidant.

Literature survey showed that when both hydrogen and chloride ions were found to catalyze the reactions involving $\mathrm{N}$-halo compounds, molecular chlorine was assumed to act as the effective oxidant and such reports were given in the oxidation of chalcones [17] and aminoacids [18]. At the lower $\mathrm{pH}$, molecular chlorine is the much more reactive species than hypochlorous acid [19]. Formation of a steady and small concentration of molecular chlorine was reported with different N-halo compounds viz., Chloramine-T [20] and N-chloro succinimide [21-26]. Rapid reactivity of the chlorine produced by different N-halo compounds was observed for oxidation of amines [27, 28], $N$-substituted amides and urea [29], and glycol [30, 31].

At present, in the presence of chloride ions, an increase in rate may be attributed to the formation of chlorine by following the given below reactions.

$$
\begin{aligned}
& \mathrm{DCICA}+\mathrm{H}_{2} \mathrm{O} \rightleftharpoons \mathrm{MCICA}+\mathrm{HOCl} \\
& \mathrm{MCICA}+\mathrm{H}_{2} \mathrm{O} \rightleftharpoons \\
& \mathrm{HOCl}+\mathrm{H}^{+} \stackrel{\mathrm{K}_{1} \rightleftharpoons}{\rightleftharpoons} \mathrm{H}_{2} \mathrm{OCl}^{+} \\
& \mathrm{H}_{2} \mathrm{OCl}^{+}+\mathrm{Cl}^{-} \stackrel{\mathrm{K}_{3}}{\rightleftharpoons} \mathrm{Cl}_{2}+\mathrm{H}_{2} \mathrm{O}
\end{aligned}
$$

From the rate constants, it is clear that the order of reactivity is: acetone $>2$-butanone, which fairly corroborate with the stability of these enols. In the present study, the rate determining step is enolisation of ketones which comprises two successive stages viz., (i) equilibrium protonation of carbonyl group and (ii) deprotonation of $\alpha$-carbon of the conjugate acid. The enolisation rate is influenced by the relative magnitudes of these two factors. Electron releasing and withdrawing groups persuade the first and second stages respectively. The reason for higher reaction rate with acetone compared to 2-butanone can understood from the inductive effect of the ethyl group tightening of protons there by increasing the relative thermodynamic stability of the keto form, which is evidenced from $\Delta S^{\ddagger}$ values (Table 3). Hence the larger content of the enol in the cases of acetone and the lesser content enol in 2-butanone is responsible for the reduced reactivity observed with 2-butanone.

Mechanism and rate law in absence of added chloride ions

As the reaction is independent of [DCICA] in absence of chloride ions, the observed rate of reaction is undoubtedly dependent on the rate of enolisation. Previously, many authors have suggested that enolisation is a slow and rate determining step when the order is zero in oxidant $[6,7,32,33]$. The observed negative dielectric effect indicates that the rate determining step must involve an interaction between an ion $\left(\mathrm{H}_{2} \mathrm{OCl}^{+}\right)$and a dipole molecule (enol form of ketone). It has been confirmed from stoichiometry that 1.5 moles of DCICA were consumed per mole of ketone. Solvent isotope studies in $\mathrm{D}_{2} \mathrm{O}$ medium show a retardation of rate. It is well known that $\mathrm{D}_{3} \mathrm{O}^{+}$is a stronger acid than hydronium ion [34] and hence this observation supports the proposed mechanism.

In absence of chloride ions, the observed rate data can be rationalized when the reaction proceeds by (a) the protonation of ketone in the acid medium to give oxonium ion, (b) enolisation of the oxonium ion in a rate-determining step, (c) attack of enolised form of ketone by $\mathrm{H}_{2} \mathrm{OCl}^{+}$in a fast step to give $\alpha$-monochlorinated ketone which on further attack by second 
$\mathrm{H}_{2} \mathrm{OCl}^{+}$gives $\alpha$-dichlorinated ketones, (d) the $\alpha$-dichlorinated ketones undergo $\mathrm{C}-\mathrm{C}$ cleavage by the attack of water molecule and further attack by another $\mathrm{H}_{2} \mathrm{OCl}^{+}$to form carboxylic acid(s) by haloform reaction (or) hydrolysis of $\alpha$-di chlorinated ketones to give $\alpha$-dihydroxy ketones which lose a water molecule to yield $\alpha$-diketone and (e) attack of third $\mathrm{H}_{2} \mathrm{OCl}^{+}$on $\alpha$-diketone yields formic acid and acetic acid for acetone and acetic acid for 2-butanone.

Hence, in absence of added chloride ions, the oxidation of ketones by DCICA in acid medium gives the final products as formic acid and acetic acid in case of acetone, and acetic acid for 2-butanone. Diketones were reported as products through a rate determining reaction between protonated form of the ketone and oxidants - N-bromo saccharin [35], Nchlorosaccharin [5], Bromamine-T [36] and N-bromosuccinimide [1]. As reported by the earlier authors, the formation of diacetyl as a product of 2-butanone with these N-halogenating agents is unlikely due to the three main reasons viz., (i) In aliphatic series, it has been observed that $\alpha$ diketone reacts with these halogenating agents much faster than the parent ketone. Separate experiments with 2-butanone and diacetyl with TCICA have proven that the diacetyl reacts more than seven times faster compared to parent ketone [37]. Hence diacetyl cannot be the final product. At best, diketone can be an intermediate product which further cleaves to carboxylic acids. (ii) In these aliphatic ketones, halogenation reactions with $\mathrm{N}$-halogenating agents go through the haloform route leading to $\mathrm{C}-\mathrm{C}$ cleavage which finally yield carboxylic acids. The reason is that cleavage occurs by the attack of water molecule on carbonyl carbon as it is much more positive due to $\pi$-bonded oxygen. The $\alpha$-carbon bearing halogens has been presumed as being more positive by those who postulated, diacetyl as final product. (iii) The possibility of $\alpha$ diketones formation only exists in N-halogenation reaction of compounds like deoxybenzoin. In such a case, due to the two rigid phenyl systems at each end, the $\mathrm{C}-\mathrm{C}$ cleavage becomes quite difficult even though the carbonyl carbon can attract water molecule for cleavage of $\mathrm{C}-\mathrm{C}$ bond. As this requires high energy with these special compounds, attack by water on $\alpha$-carbons displaces halogens leading to diketone - benzil as the final product, because benzil cannot be cleaved by $\mathrm{N}$-halo compounds as proven by independent experiments.

Hence, at this condition, the formation of diacetyl is very unlikely and even it is formed to small extent, it certainly cleaved to carboxylic acids. This can be further substantiated by some of the earlier reports that carboxylic acids were reported as major products when the oxidation occur in acid medium through a rate determining attack on the enol form of ketone by different oxidants viz., CAT [38], bromate [39] and permanganate [40, 41]. This supports the proposed mechanism in absence of added chloride ions.

Rate law, for the above mechanism, comes out as

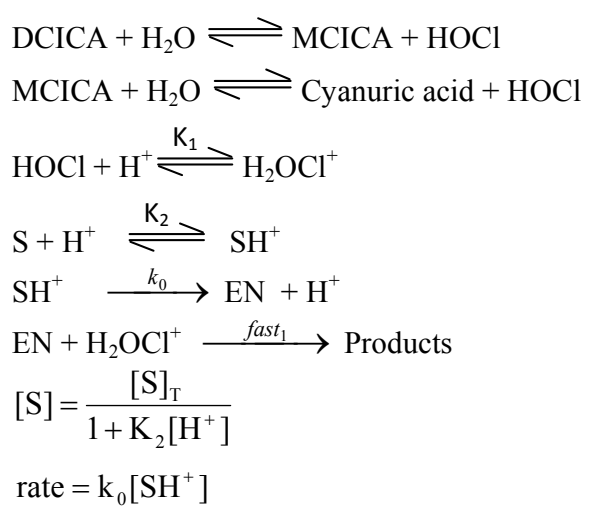




$$
\begin{aligned}
& =\mathrm{k}_{0} \mathrm{~K}_{2}[\mathrm{~S}]\left[\mathrm{H}^{+}\right] \\
& =\frac{\mathrm{k}_{0} \mathrm{~K}_{2}[\mathrm{~S}]_{\mathrm{T}}\left[\mathrm{H}^{+}\right]}{1+\mathrm{K}_{2}\left[\mathrm{H}^{+}\right]}
\end{aligned}
$$

This rate expression is consistent with observed kinetics in the absence of chloride ion, viz., zero order with respect to [DCICA] and first order in [ketone] and fractional order with respect to $\left[\mathrm{H}^{+}\right]$.

\section{Mechanism and rate law in presence of added chloride ions}

In the presence of chloride ions, the unit order with respect to both [DCICA] and [substrate] indicates that probably they were not involved in the formation of any kind of complex, or even if the complex is formed it was assumed to be highly unstable. In presence of added chloride ions, the most probable steps of ketones reaction with DCICA can be given as (i) the protonation of ketone in the acid medium, (ii) formation of chlorine due to reaction of added chloride ions with hypochloronium ion $\left(\mathrm{H}_{2} \mathrm{OCl}^{+}\right)$, (iii) formation of complex in a rate determining step between protonated ketone with $\mathrm{Cl}_{2}$ and (iv) break down of the complex by $\mathrm{C}-\mathrm{C}$ cleavage due to attack of water molecule on carbonyl carbon, leading finally to the formation of carboxylic acid by the usual haloform route (or) the complex rapidly breaks down in a series of steps to give dihydroxy ketone which finally cleaves to carboxylic acids.

Finally, in the presence of chloride ions, the final products were formic acid and acetic acid for acetone whereas, it was acetic acid for 2-butanone as observed even in the absence of chloride ions.

For the above mechanism, the rate law can be given as

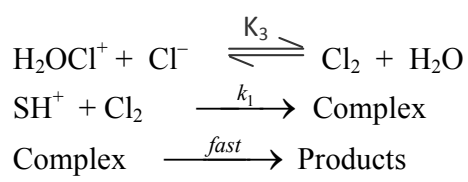

The rate expression consistent with observed kinetics viz., first order with respect to oxidant and substrate, and fractional order with respect to $\left[\mathrm{H}^{+}\right]$and $\left[\mathrm{Cl}^{-}\right]$is given below.

$$
\begin{aligned}
\text { rate } & =\mathrm{k}_{1}\left[\mathrm{SH}^{+}\right]\left[\mathrm{Cl}_{2}\right] \\
& =\frac{\mathrm{k}_{1} \mathrm{~K}_{2} \mathrm{~K}_{3}[\mathrm{DCICA}]\left[\mathrm{H}^{+}\right]\left[\mathrm{Cl}^{-}\right][\mathrm{S}]_{\mathrm{T}}}{\left(1+\mathrm{K}_{3}\left[\mathrm{Cl}^{-}\right]\right)\left(1+\mathrm{K}_{2}\left[\mathrm{H}^{+}\right]\right)}
\end{aligned}
$$

\section{CONCLUSIONS}

In the oxidation of ketones by DCICA in acid medium, hypohalous acidium ion $\left(\mathrm{H}_{2} \mathrm{OCl}^{+}\right)$and molecular chlorine $\left(\mathrm{Cl}_{2}\right)$ were the active oxidizing species in the presence and absence of added chloride ions respectively. The probable mechanisms involve (i) rate-determining enol formation from the conjugate acid $\left(\mathrm{SH}^{+}\right)$of the ketone in the absence of added chloride ions and (ii) rate-determining interaction of $\mathrm{SH}^{+}$with the most effective molecular chlorine species in the presence of added chloride ions. Higher oxidation rate in acetone than 2-butanone can be attributed to inductive effect of the methyl group tightening of protons there by increasing the relative stability of the keto form. Both in absence and presence of added chloride ions, the final products were formic acid and acetic acid for acetone whereas, it was acetic acid for 2-butanone due to an interaction between a positive ion and a dipolar molecule. 


\section{REFERENCES}

1. Giridhar Reddy, P.; Ramesh, K.; Shylaja, S.; Rajanna, K.C.; Kandlikar, S. Sci. World J. 2012, Article ID 456516, doi:10.1100/2012/456516.

2. Mushran, S.P.; Singh, K.; Pandey, L.; Pandey, S.M. Proc. Indian Natl. Sci. Acad. 1980, 46, 119.

3. Madhavi, N.; Sundar, B.S.; Radhakrishnamurti, P.S. Oxid. Commun. 2006, 29, 304.

4. Khan, S.; Khan, M.U.; Sanjay Kumar, S.; Gupta, H.D.; Singh, P.K. Asian J. Chem. 2003, 15, 595.

5. Khan, S.; Nigam, S.K.; Dwivedi, H.P.; Singh, P.K. Asian J. Chem. 2004, 16, 751.

6. Radhakrishnamurti, P.S.; Rath, N.K. Indian J. Chem. 1985, 24A, 300.

7. Radhakrishnamurti, P.S.; Rath, N.K.; Panda, R.K. J. Chem. Soc., Perkin Trans. II 1987, 4, 517.

8. Mohan, K.V.; Raghunath Rao, P.; Sundaram, E.V. J. Indian Chem. Soc. 1984, 61, 225.

9. Weast, R.C. (Ed.) CRC Handbook of Chemistry and Physics, CRC Press: Ohio, OSA; 1978.

10. Reichardt, C. Solvent and Solvent Effects in Organic Chemistry, 3rd ed., Wiley-Vett: New York; 2003; p 219.

11. Littler, J.S.; Waters, W.A. J. Chem. Soc. 1959, 1299.

12. Kolthoff, M.; Meehan E.J.; Carr, E.M. J. Am. Chem. Soc. 1953, 75, 1439.

13. Mahesh, R.T.; Bellakki, M.B.; Nandibewoor, S.T. Catal. Lett. 2004, 97, 91.

14. Anil Kumar, J.; Sondu, S. Indian J. Chem. 2007, 46A, 1792.

15. Venkateswaralu, S.; Jagannadham, V. Indian J. Chem. 1988, 27A, 314

16. Mathiyalagan, N.; Sridharan, R.; Priya, V. J. Indian Chem. Soc. 2005, 82, 795.

17. Parimala Vaijayanthi, S.; Mathiyalagan, N. Int. J. Res. Pharm. Chem. 2012, 2, 722.

18. Mahadevappa, D.S.; Rangappa, K.S.; Gowda, N.M.M. Indian J. Chem. 1981, 2A, 263.

19. Sarkanen. K.V. Pure Appl. Chem. 1962, 5, 219.

20. Kiranmai Kolachana1, V.S.; Kishore, C.; Kayani1, W.M.; Kouassi1, G.K.; Jagadeesh, R.V.; Made Gowda, N.M. Am. J. Org. Chem. 2012, 2, 18

21. Carr, M.D.; England, B.D. Proc. chem. Soc. 1958, 350.

22. Pearson, R.E.; Martin, J.C. J. Am. Chem. Soc. 1963, 85, 354.

23. Srinivasan, N.S.; Venkatasubramanian. N. Tetrahedron Lett. 1970, 24, 2039.

24. Srinivasan, N.S.; Venkatasubramanian, N. Tetrahedron. 1970, 30, 419.

25. Vivekanandan, K.; Nambi, K. J. Indian Chem. Soc. 1999, 76, 198.

26. Priya, V.; Balasubramaniyan, M.; Mathiyalagan, N. J. Chem. Pharm. Res. 2011, 3, 522.

27. Deborde, M.; Von Gunten U. Water Res. 2008, 42, 13.

28. Margerum, D.W.; Gray, E.T.; Huffman, R.P. Chlorination and the Formation of N-Chloro Compounds in Water Treatment in Organometals and Organometalloids: Occurrence and Fate in the Environment, Brinckman, F.E.; Bellama, J.M. (Eds.), American Chemical Society: Washington, DC; 1978; p 278.

29. Thomm, E.W.C.W.; Wayman, M. Can. J. Chem. 1969, 47, 3289.

30. Bhagwat, V.W.; Tiwari, J.; Choube, A.; Pare, B. J. Serb. Chem. Soc. 2003, 68, 535.

31. Vandana Sharma, K.V.; Bhagwat, V.W. E-J. Chem. 2008, 5, 894.

32. Littler, J.S.; Waters, W.A. J. Chem. Soc. 1962, 827.

33. Vasudevan K.S.; Venkatasubramanian, N. Indian J. Chem. 1985, 24A, 304.

34. Kohen, A.; Limbach, H.H. Isotope Effects in Chemistry and Biology, CRC Press: Florida; 2006; $\mathrm{p} 827$.

35. Vijayamohan, K.; Rao, P.R.; Sundaram, E.V. J. Indian Chem. Soc. 1988, 65, 91.

36. Mahadevappa, D.S.; Swamy, P. Bull. Chem. Soc. Jpn. 1988, 61, 543.

37. Subba Rao, T.L.M.V. Study of chemical dynamics of some oxidation reactions, Ph.D. Thesis, Acharya Nagarjuna University, India, 2009.

38. Singh, K.J.; Raina, N. J. Indian Chem. Soc. 1977, 54, 482.

39. Krishnamurthy, N.; Reddy, C.H.S.; Sundaram, E.V. Indian J. Chem. A 1989, 28, 288.

40. Marigangaiah, N. P.; Banerji, K.K. Aust. J. Chem. 1976, 29, 1939.

41. Radhakrishnamurti, P.S.; Rao, M.D.P. Indian J. Chem. A. 1977, 15, 524. 